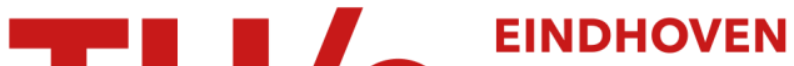 \\ UNIVERSITY OF \\ TECHNOLOGY
}

\section{Design and modelling of a modular robot system}

\section{Citation for published version (APA):}

Mulders, P. C., Kreffer, G. J., Bax, W. H. M., \& van der Wolf, A. C. H. (1993). Design and modelling of a modular robot system. CIRP Annals : Manufacturing Technology, 42(1), 429-432. https://doi.org/10.1016/S00078506(07)62478-0

DOI:

10.1016/S0007-8506(07)62478-0

Document status and date:

Published: 01/01/1993

\section{Document Version:}

Publisher's PDF, also known as Version of Record (includes final page, issue and volume numbers)

\section{Please check the document version of this publication:}

- A submitted manuscript is the version of the article upon submission and before peer-review. There can be important differences between the submitted version and the official published version of record. People interested in the research are advised to contact the author for the final version of the publication, or visit the $\mathrm{DOI}$ to the publisher's website.

- The final author version and the galley proof are versions of the publication after peer review.

- The final published version features the final layout of the paper including the volume, issue and page numbers.

Link to publication

\section{General rights}

Copyright and moral rights for the publications made accessible in the public portal are retained by the authors and/or other copyright owners and it is a condition of accessing publications that users recognise and abide by the legal requirements associated with these rights.

- Users may download and print one copy of any publication from the public portal for the purpose of private study or research.

- You may not further distribute the material or use it for any profit-making activity or commercial gain

- You may freely distribute the URL identifying the publication in the public portal.

If the publication is distributed under the terms of Article 25fa of the Dutch Copyright Act, indicated by the "Taverne" license above, please follow below link for the End User Agreement:

www.tue.nl/taverne

Take down policy

If you believe that this document breaches copyright please contact us at:

openaccess@tue.nl

providing details and we will investigate your claim. 


\title{
Design and Modelling of a Modular Robot System
}

\author{
P. C. Mulders (2), G. J. Kreffer, W. H. M. Bax, A. C. H. van der Wolf (1), \\ Eindhoven University of Technology/Netherlands \\ Received on January 15, 1993
}

\begin{abstract}
A modular robot system - consisting of a linear and a rotary actuator and for loads up to $50 \mathrm{~kg}$ - has been developed. The linear robot arm is driven by a DC motor, has a length of $1 \mathrm{~m}$, a maximum velocity of $1 \mathrm{~m} / \mathrm{s}$, an acceleration of $5 \mathrm{~m} / \mathrm{s}^{2}$ and an accuracy of $0.01 \mathrm{~mm}$. The rotational module is also driven by a DC motor with an angular velocity of $\pi / 2 \mathrm{rad} / \mathrm{s}$, an acceleration of $\pi / 2 \mathrm{rad} / \mathrm{s}^{2}$ and an accuracy of $10^{-5} \mathrm{rad}$. With a 3D-force sensor teach - and replay of trajectories will be performed.

Optimal trajectory control strategies - like e.g. the optimal control law by matrix riccati, the computed torque or model reference adaptive control (MRAC) method - are based on a good knowledge of the system.

(Mom this modular rost an extended dynamic model has been made, which is verified by modal analysis techniques.

Next a model reduction has been done - to obtain a simulation model or a control model - and this is necessary to test adaptive path control algorithms with respect to the phenomena of parameter varations during trajectory performance.
\end{abstract}

KEYWORDS: Mechatronics, simulation, computer adaptive control.

\section{NTRODUCTION}

In order to obtain experience in robot design and to test advanced control systems as well, a modular robot system for loads up to $50 \mathrm{~kg}$ has been developed, which will consist of linear and rotary actuators. One of each type has been constructed and built together in the mean time, as shown in Fig.1.

The linear robot arm is driven by a DC motor of $1 \mathrm{~kW}$, has a length of $1 \mathrm{~m}, \mathrm{a}$ maximum velocity of $1 \mathrm{~m} / \mathrm{s}$, an acceleration of $5 \mathrm{~m} / \mathrm{s}^{2}$ and an accuracy of 0.01 mm.

The rotational module is also driven by a $\mathrm{DC}$ motor of $1 \mathrm{~kW}$, has an angular velocity of $\pi / 2 \mathrm{rad} / \mathrm{s}$, and angular acceleration of $\pi / 2 \mathrm{rad} / \mathrm{s}^{2}$ and an angular accuracy of $10^{-5}$ rad. So the tangential accuracy is of the same order as the radial accuracy

The aim of this work is also to study optimal (adaptive) control algorithms on systems with place- and time dependent parameters during trajectory systems with place- and time dependent parameters during trajectory performance and to try this out on practical systems of industrial scale.
Experiments on this item already have been done with the lineair robot arm [1] and with the modular robot [2].

The optimal algorithm of the controller is based on the minimization of a performance criterion-function and so the control signals are obtained.

The performance integral may contain e.g. contributions of the deviations in trajectory positions and velocities but also the control efforts like the motor control signals. Even the boundaries for the control signals may be taken into account.

The updating of the parameters in the algorithm for adaptive control depends on the time to solve the matrix-riccati equation and this is strongly dependent on the number of the state-space dimensions of the model.

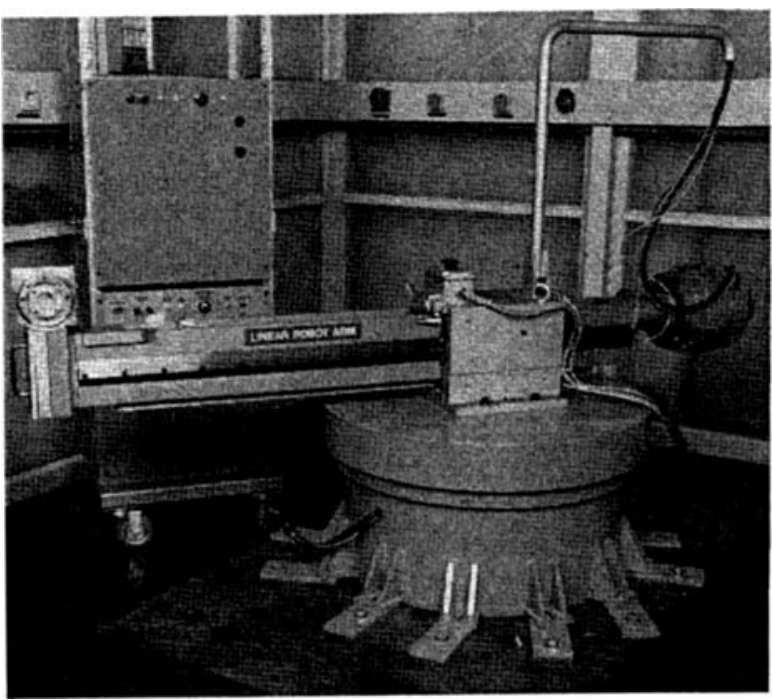

Fig. 1. Photograph of the modular robot system.

So optimal trajectory control algorithms are based on a good knowledge of the system, but on the other hand these models should not be too complex, because they might increase the computation time of the optimal control law so that on line control becomes impossible.

Besides of the optimal control law method a number of other optimal trajectory control strategies can be mentioned e.g.

- the PID method

- the computed torque method [2]

the model reference adaptive control (MRAC) method. [2]

All these algorithms are based on a good knowledge of the system. So from this modular RT robot system an extended model - simulation model - has been

made, which is verified by modal analysis techniques. Next this extended model has been reduced - to a control model - to enable on line computation of the optimal trajectory control signals. See Fig. 5

\section{DESIGN OF THE MODULAR ROBOT.}

A view of this modular robot system is given in Fig. 2.

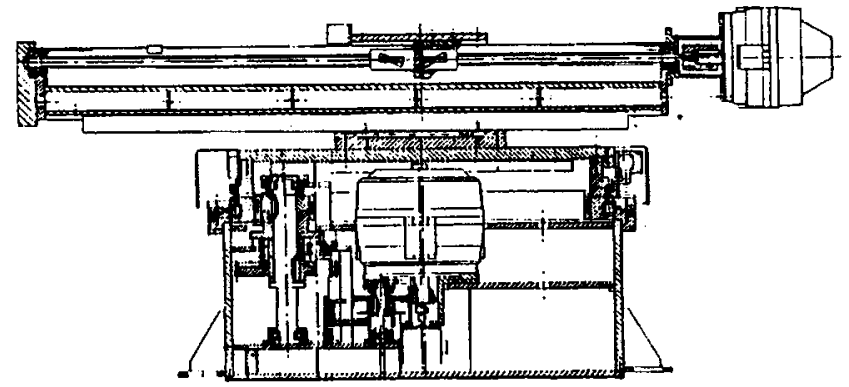

Fig. 2 View of the modular robot system

2.1 The construction of the linear robotarm.

The major specifications of the linear actuator are shown in Table 1.

maximum velocity

maximum acceleration

maximum load

stroke

position accuracy

position measuring system

power source

control system

$$
\begin{aligned}
& 1 \mathrm{~m} / \mathrm{s} \\
& 5 \mathrm{~m} / \mathrm{s}^{2} \\
& 50 \mathrm{~kg} \\
& 1 \mathrm{~m} \\
& 0.01 \mathrm{~mm} \\
& \text { Heidenhain LS } 513 \\
& \text { DC-motor: Axem MC 19 PR } 26 \\
& \mu C \text { PID - or state controller }
\end{aligned}
$$

Table 1. Design specifications of the linear robotann.

The mechanical construction is fairly stiff due to the hollow frame construction, while at the same time the masses are kept minimal.

The arm has been constructed with side guide-ways, which enables the preloading of the spindle and the application of roller bearings for the main bearing system.

The rotation of the motor into a transiation of the actuator is converted by a spindle with a ballscrew nut. An advantage of this combination is that the back-lash can be eliminated by preloading the nut.

A disadvantage is that the rotary speed is limited because of the critical speed of the spindle.

The DC motor is of the disc-armature type with the following characteristics: - a very small mechanical time constant. With a load of $50 \mathrm{~kg}$ this becomes 26 ms.

- a continuously adjustable speed

- the largest torque at low speed.

The disadvantage however is the poor resistance against overheating. This is important because the criterion for design was very determined by the $100 \%$ duty cycle. Coupled to the motorshaft is also a tachogenerator and a rotational encoder.

For direct position measurement along the arm an optical linear digital incremental encoder has been mounted, type Heidenhain LS513 with a length of $1020 \mathrm{~mm}$ and an accuracy of $0.01 \mathrm{~mm}$. The necessary frequency range of the encoder is determined by the speed of the arm and the accuracy of the scale.

The free end of the linear robotarm is extended with a 3D-force sensor, based on the bending principle and measured by strain gauges. The force sensor is used in the TEACH mode.

\subsection{The construction of the rotational module.}

The major specifications are shown in Table 2. 
maximum angular velocity maximum angular acceleration maximum angular range position measuring system power source control system position accuracy

$\pi / 2 \mathrm{rad} / \mathrm{s}$

$\pi / 2 \mathrm{rad} / \mathrm{s}^{2}$

$\pi \rightarrow 2 \pi \mathrm{rad}$

$10^{-5} \mathrm{rad}$

Heidenhain LIDA 360

DC-motor: BBC-MC 19P

$\mu \mathrm{C}$ PID - or state controller

Table 2. Design specifications of the rotational module

The mechanical construction is based on a cylinder with side ribs - to minimize the deformation - and is fixed to a groundplate.

The transmission from the motor to the turntable consists of a 4 stage toothed wheel combination with divided and preloaded wheels - realized with torsion springs - to eliminate backlash. The toothweels $2,3,5$ and 7 are divided and preloaded, so each conversion is backlash-free.

The transmission ratios - starting from the motorside - as the quotient of the number of teeth are respectively: 45/21:83/21;83/23 and $136 / 23$ and gives a total reduction of 181

This transmission has been chosen after considering alternatives with toothed wheel combinations and a harmonic drive. The selection criteria were: the transmission ratio, the stiffness, the efficiency, the backlash, the moment of inertia and the height of the construction.

The range of the rotational module is - like the linear actuator - limited by Hall switches.

The DC motor BBC-AXEM MC $19 \mathrm{P}$ is of $1 \mathrm{~kW}$ and of the disc armature type and driven by the recommended amplifier $05 \mathrm{LV} 05$ of $\mathrm{BBC}$. Coupled to the motor shaft is also a tachogenerator and a rotational encoder. For direct position measurement of the turntable an optical digital incremental encoder as a lineal has been mounted along the circumference of the turntable type Heidenhain LIDA 360 with 20200 lines and a pulse shaper EXE-702, and an interpolation factor of $1 ; 5$ and 25 and a subdivider of $1 ; 2$ and 4 . By this the accuracy may be multiplied by $25 \times 4=100$.

The various components as the moment of inertia, stiffness, damping etc. are given in the model description in Ch. 4

\section{THE CONTROL SYSTEM OF THE MODULAR ROBOT.}

\subsection{The hierarchical control structure.}

The on-line computer-capacity of one controller is often too small or not fast enough to implement an advanced control algorithm in real time.

The controller system consists of 4 Intel single board computers - working in parallel - and 1 RAM board.

The boards can communicate directly - i.e. the interrupts - via the multibus system. Data however are transported to each other via the common

RAM-board 028 .

The rotation as well as the translation is controlled by its own board Intel SBC $186 / 03$, coupled to its own input (the measuring system) and its own output (the motoramplifier) by the Intel SBX-interfaces.

The task of each SBC 186/03 is:

to calculate - according to a control algorithm - the motor voltages

to read the position of each module

to store these data - motor voltages and positions - into the RAM board.

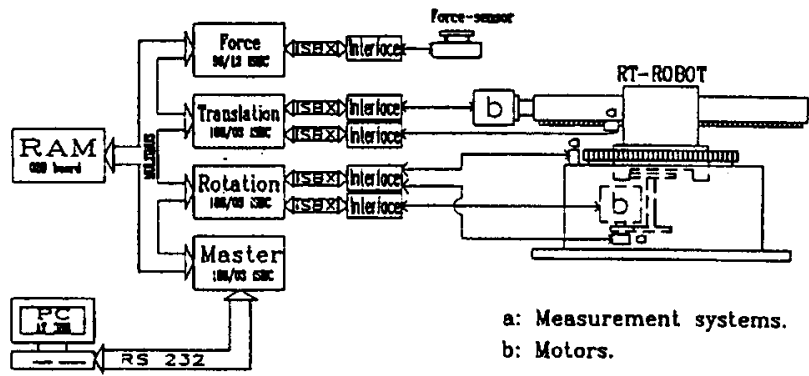

Fig. 3. The hierarchical controller system.

The 3D-force sensor is coupled - with its Intel SBX interface - to the multibus by the Intel SBC $86 / 12$.

The Intel SBX-bus is a very fast 16 bits I/O channel. A motor interface consists of a 12 bit DAC to convert a digital into an analog signal for the motor-amplifier. The motor interface may conduct moreover a signal from the Hall-switches. The rotation - and translation position interfaces consist of a 20 Hall-switches. The rotation - and translation position interfaces cons
bits counter based on the counterchip 74 LS 2000 . This chip has a direction-decoder and may perform a dynamic interpolation to a factor 4 .

The task of the master SBC $186 / 03$ is to:

synchronize the software in both the other SBC's

transfer data over the RS 232 bus.

A PC 80386 is coupled to the Master SBC. In this PC software may be developed and tested. By a data switch it can be used as a terminal for each SBC.

The optimal control law and the nominal trajectory is calculated off-line by this computer and the results are transmitted to the SBC's

The $\mathrm{PC}$ also serves to diagram the measurement data.
3.2 Trajectory control strategies.

The statement that a good controller is based on the best estimate of the system structure is considered in a simplified way shown in Fig. 4.

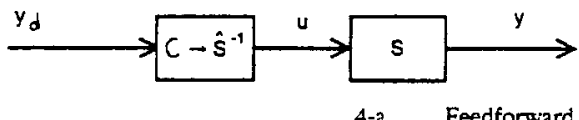

4-a Feedforward
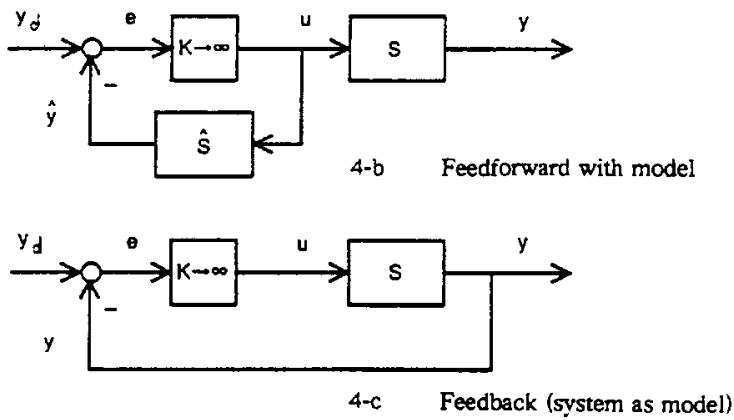

Fig. 4. Feedforward-and feedback control

If a system $\mathbf{S}$ needs to perform a certain trajectory $y$ then the problem is to determine the necessary input signal $u$ from that response. The best feedforward controller $\mathrm{C}$ would be the inverse of the best estimate of the system, so $C \rightarrow \hat{S}^{-1}$. However, as any physical system has a less or an equal number of zeros than poles this means that $\mathrm{C} \rightarrow \hat{S}^{-} \mathbf{l}$ should have the opposite and needs to have predictive properties and can not be realized. The desired controller $\mathrm{C} \rightarrow \hat{\mathrm{S}}^{-1}$ is easily obtained by the feedback loop and increasing the open loop gain $K \rightarrow \infty$ over the frequency range (4-b). from $C=\left(\frac{1}{K}+\hat{S}\right)^{-1}$.

At the transition to (4-c) the system $S$ itself is used as the model, so with $\mathrm{K} \rightarrow \infty$ over the frequency range a feedback controlled system is created.

In the keynote paper at CIRP 1992 "Advanced controllers for feed drives" from Y. Koren and C.C. Lo more detailed controllers are discussed. [12)

Optimal (adaptive) trajectory control algorithms are applied on systems with place - and time dependent parameters during trajectory performance.

A number of strategies may be mentioned here e.g.

- P.I.D. method

- computed torque method [2]

- the model reference adaptive control (MRAC) method [2]

- the optimal control law with performance index [1]

All these strategies are based on a good knowledge of the system. Only the optimal control law with performance index will be described more in detai (Fig. 5).

On the modular robot system a 3D-force sensor is mounted to perform teachand replay trajectory operations. The desired trajectory is known or firstly carried out by the robot by movement of the end effector with the 3D-force sensor. The positions of the end-effector represent that desired trajectory and by identification (Control model - computed torque method) a related sequence of motor input signals is obtained. Then the desired trajectory is again performed motor input signals is obtained. Then the desired trajectory is again performed eventually with varying parameters in which the already known motor control
signals are updated - by state feedback - by the new control algorithm, as shown in Fig. 5.

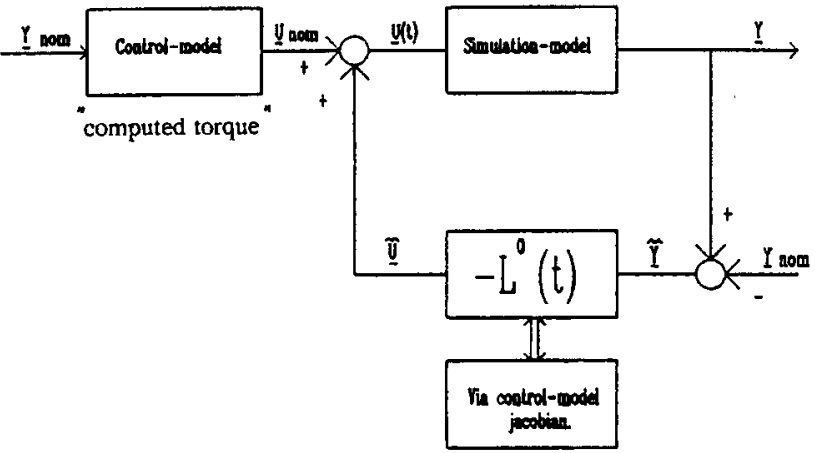

Fig. 5 Computed torque and optimal control of the modular robot

This control law is based on a description of the robot by a state-space model, according to:

$$
x(t)=A(t) x(t)+B(t) \underline{u}(t)
$$

The optimal control law $L^{0}(t)$ is defined as

$$
L^{0}(t)=R^{-1}(t) B^{T}(t) P^{0}(t)
$$

in which $R$ is the weighing matrix for the control signals in the performance integral and the optimal $P^{0}(t)$ is found by solving the matrix-riccati equation: 
$-P^{0}(t)=A^{T}(t) P^{0}(t)+P^{0}(t) A(t)+Q(t)-P^{0}(t) B(t) R^{-1}(t) B^{T}(t) P^{0}(t)$

(3)

The updating of the parameters in the algorithm for adaptive control depends on the time to solve the matrix-riccati equation and this is strongly dependent on the number of the state-space dimensions of the model.

So optimal trajectory control algorithms are based on a good knowledge of the system, but on the other hand these models should not be too complex, because they might increase the computation time of the optimal control law-according to (2) and (3) - so that on line control becomes impossible.

4. MODELLING OF THE MODULAR ROBOT.

Although the modular robot has been constructed with many distinct components, each one with its own properties like mass, stiffness etc, the combination leads to a system with divided parameters.

In this chapter an attempt is made to realize a lumped mass model - with artificial components - which describes the behaviour of the robot as good as possible.

This approach is a.o. based on previous studies [3] about drives of motor-tacho-spindle-carriage combinations.

For the linear actuator this means e.g. that to the moment of inertia of the motor is added the half of the spindle-part between motor and ballscrew nut plus coupling and so this parameter varies also with the radial position of the linear actuator.

At the rotational module each spindle has at each side a toothed wheel, so the moment of inertia at each side consists of two components concerning wheel and half of the spindle. $J_{9}^{R}$ is the combination of the moment of inertia of the turntable, the measuring system and the linear actuator and so dependent of its radial position $x(t)$.

An extended model of both modules is given in Fig. 6

\section{ROTATION}
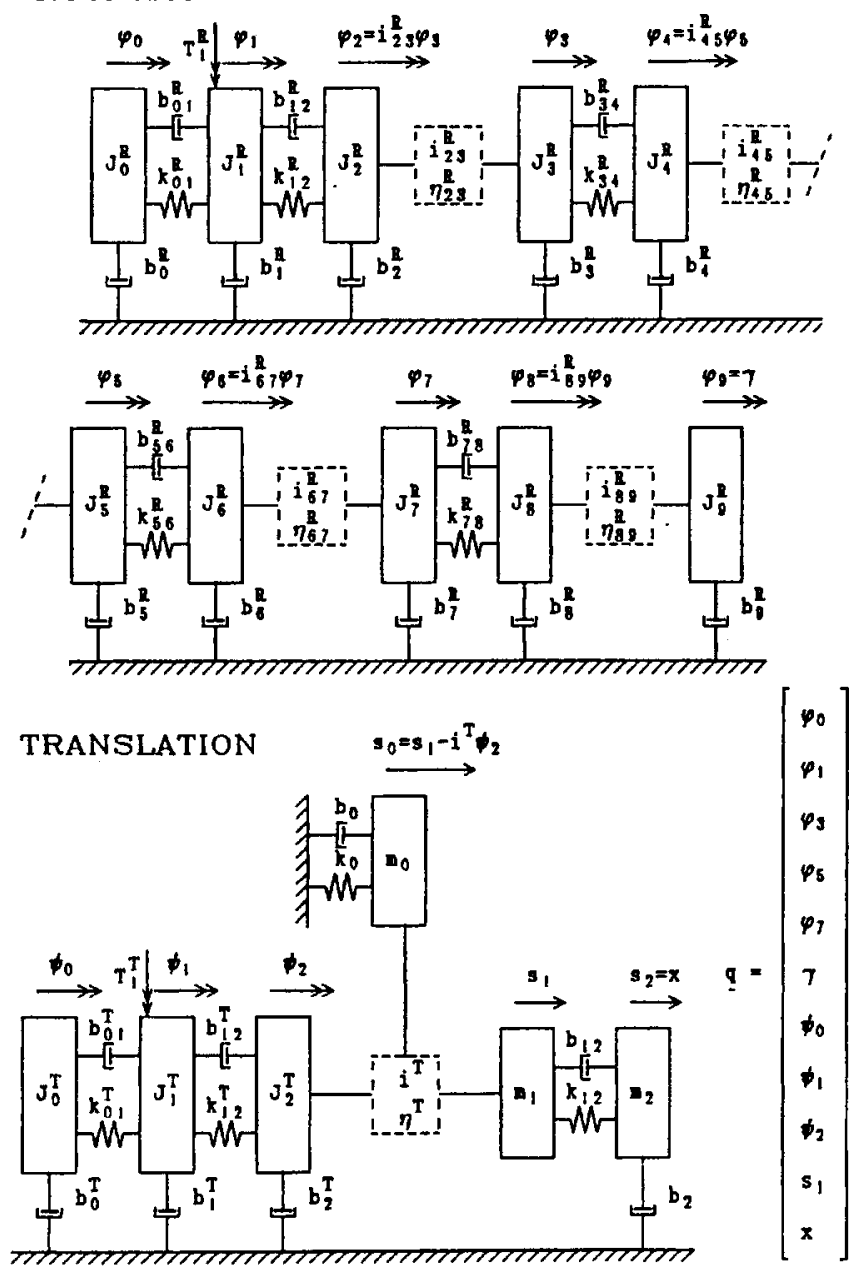

Fig. 6. Extended model of the modular robot system.

The presented model of Fig. 6 has 11 degrees of freedom.

$q^{T}=\left(\varphi_{0} \varphi_{1} \varphi_{3} \varphi_{5} \varphi_{7} \gamma \psi_{0} \psi_{1} \psi_{2} s_{1} x\right)$

The rotation and translation are coupled to each other, so also the eigenfrequencies. These are also dependent on the position $x(t)$ of the linear actuator (varying from -0.270 to $+0.365 \mathrm{~m}$ ) and an eventual load $m_{L}[\mathrm{~kg}]$.

\begin{tabular}{|c|c|ccccccccc|}
\hline $\mathrm{m}_{\mathrm{L}}[\mathrm{kg}]$ & $\mathrm{x}(\mathrm{t})[\mathrm{m}]$ & $\mathrm{f}_{1}$ & $\mathrm{f}_{2}$ & $\mathrm{f}_{3}$ & $\mathrm{f}_{4}$ & $\mathrm{f}_{5}$ & $\mathrm{f}_{6}$ & $\mathrm{f}_{7}$ & $\mathrm{f}_{8}$ & $f_{9}$ \\
\hline \multirow{3}{*}{0} & -0.270 & 18 & 110 & 182 & 284 & 366 & 435 & 445 & 488 & 6590 \\
\cline { 2 - 10 } & 0 & 20 & 122 & 182 & 284 & 371 & 439 & 445 & 506 & 6590 \\
\hline \multirow{3}{*}{50} & +0.365 & 19 & 134 & 182 & 284 & 377 & 443 & 445 & 528 & 6590 \\
\cline { 2 - 9 } & -0.270 & 17 & 98 & 182 & 284 & 366 & 435 & 445 & 487 & 6590 \\
\hline & 0 & 17 & 109 & 182 & 284 & 371 & 439 & 445 & 505 & 6590 \\
\hline
\end{tabular}

Table 3. Eigenfrequencies of the coupled system $[\mathrm{Hz}]$.

4.1 Model of the linear actuator.

If the degrees of freedom are represented by the vector $\mathrm{q}$, the external moments by $Q$ and with $M$ the mass-matrix, $D$ the damping-matrix and $K$ the stiffness-matrix in which:

$\mathfrak{q}^{T}=\left(\psi_{0}, \psi_{1}, \psi_{2}, s_{1}, x\right)$ and $Q^{T}=\left(0, T_{1}^{T}, 0,0,0\right)$

the linear actuator is described by the differential equation:

$M \ddot{\mathrm{q}}+\mathrm{D} \dot{\mathrm{q}}+\mathrm{Kq}=\mathrm{Q}$

The motor torque $T_{1}^{T}$ acts on moment of inertia $\mathrm{J}_{1}^{\mathrm{T}}$.

For the estimation of the lowest eigenfrequency a single- D.O.F. system is considered. A moment of inertia $J_{i}$ is transferred to a mass $m_{i}=J_{i}\left(2 \pi / h_{S p}\right)^{2}$.

The masses can be transferred and summarized to the end of the chain of masses and the springs- applied in series- can be reduced to one spring constant.

$$
I_{/ k}=\sum_{i=1}^{n} 1_{/ k_{i}} \quad m_{T, j}=m_{j}\left(\frac{\sum_{i=1}^{j} 1_{/ k}}{1_{/ k}}\right)^{2}
$$

With the respectively data the lowest eigenfrequency $f_{0}$ becomes:

$$
\mathrm{m}=125 \mathrm{~kg} \quad \mathrm{k}=1,310^{7} \mathrm{~N} / \mathrm{m} \quad \mathrm{f}_{0}=\frac{1}{2 \pi} \sqrt{-\frac{k}{\mathrm{~m}}}
$$

$$
\mathrm{f}_{0}=110 \stackrel{\circ}{\div} 134[\mathrm{~Hz}]
$$

The dynamic model of the linear robotarm has been measured with a Fourier analyzer (HP 5423) and calculated with a special programme. The value of $f_{0}$ depends on the position $x(t)$ of the linear actuator.

\begin{tabular}{|c|c|ccc|}
\hline $\mathbf{x}(\mathrm{t})$ & {$[\mathrm{m}]$} & -0.27 & 0 & 0.365 \\
\hline $\mathbf{f}_{0}$ & {$[\mathrm{~Hz}]$} & 110 & 122 & 134 \\
\hline
\end{tabular}

If the linear actuator is considered as the extended model then the other eigenfrequencies $[\mathrm{Hz}]$ are:

\begin{tabular}{|cccc|}
\hline$f_{2}$ & $f_{5}$ & $f_{6}$ & $f_{8}$ \\
\hline 122 & 371 & 439 & 506 \\
\hline
\end{tabular}

4.2 Model of the rotational module.

The rotational module may also be described by:

$\mathrm{M} \ddot{\mathrm{q}}+\mathrm{D} \dot{\mathrm{q}}+\mathrm{Kq}=\mathrm{Q}$

with $\mathrm{q}^{\mathrm{T}}=\left(\varphi_{0}, \varphi_{1}, \varphi_{3}, \varphi_{5}, \varphi_{7} \gamma\right)$ and $\mathrm{Q}^{\mathrm{T}}=\left(0, \mathrm{~T}_{1}^{\mathrm{R}}, 0,0,0,0\right)$

The motor torque $T_{1}^{R}$ acts on moment of inertia $J_{1}^{R}$.

For the estimation of the lowest eigenfrequency $f_{0}$ a single D.O.F- system is considered, like in the model of the linear actuator.

The lowest eigenfrequency is $\mathrm{f}_{0}=18 \stackrel{\circ}{\circ} 20 \quad[\mathrm{~Hz}]$

The value of $\mathrm{f}_{0}$ depends on the position $x(t)$ of the linear actuator.

\begin{tabular}{|c|c|ccc|}
\hline$x(t)$ & {$[m]$} & -0.27 & 0 & 0.365 \\
\hline $\mathrm{f}_{0}$ & {$[\mathrm{~Hz}]$} & 18 & 19.5 & 18.9 \\
\hline
\end{tabular}

If the rotation-module is considered as the extended model then the other eigenfrequencies $[\mathrm{Hz}]$ are:

\begin{tabular}{|lllll|}
\hline$f_{1}$ & $f_{3}$ & $f_{4}$ & $f_{7}$ & $f_{9}$ \\
\hline 19.5 & 182 & 284 & 445 & 6590 \\
\hline
\end{tabular}




\subsection{Model reduction.}

The necessity to make an extended model (Fig. 6) with 11 degrees of freedom (D.O.F.) (rotation 6 and translation 5) is based on the idea to describe the reality as good as possible. The behaviour of the robot may so be predicted over the complete frequency - or time domain.

Nevertheless there will always be a discrepancy between reality and the simulation model due to unmodelled dynamics. A disadvantage will also be the duration of a simulation result, specially if a small time step is applied. By reducing the complexity (less D.O.F.) of the simulation model a compromise is made between the accuracy and the duration. But there is another reason for model reduction, i.e. the realization of a controller via a control model.

As elucidated in Ch. 3.2 "Trajectory control strategies" a controller like the optimal -or adaptive control law) is based on the system knowledge (model). The controller is even frequently updated by solving the matrix riccati equation - if the parameters change during trajectory performance.

By this reason the on-line controller is based on a simpler control model and so a balance is made between accuracy and time. In spite of the model reduction the derived controller should be robust enough with respect to control phenomena like stability.

Model reduction is arbitrary and some methods are known e.g. Guyan. In general the lowest eigenfrequency has most influence on the system dynamics and this one should be present in the reduced model. Considering the eigen

\section{ROTATION TRANSLATION}
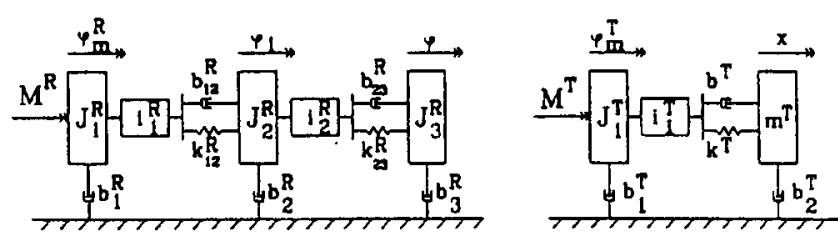

$$
\underline{q}=\left[\begin{array}{l}
\varphi_{m}^{R} \\
\varphi_{1} \\
\varphi \\
\varphi_{m}^{\mathrm{T}} \\
x
\end{array}\right]
$$

$\mathrm{J}_{3}^{\mathrm{R}}=\mathrm{F}(\mathrm{x})$
ROTATION

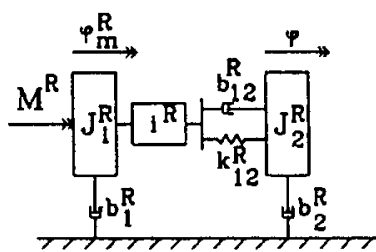

ROTATION

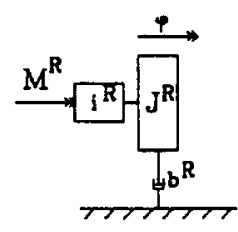

Fig. 7 Reduced models of the rotation-translation robot.

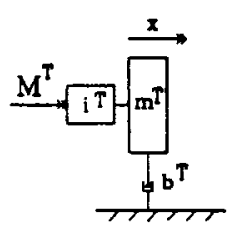

TRANSLATION

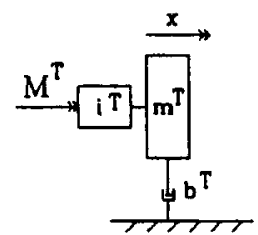

TRANSLATION
$\underline{q}=\left[\begin{array}{c}\varphi_{m}^{R} \\ \varphi \\ x\end{array}\right]$

$J_{2}^{R}=F(x)$

$\underline{q}=\left[\begin{array}{l}\varphi \\ x\end{array}\right]$

$J^{R}=F(x)$

The combination of the translation- and rotational module however are a challenge to the adaptive control system during trajectory performance. [1] [2] The behaviour of the real system may be very well described by an extended model with 11 D.O.F.

For simulation experiments with a controller the robot can be described by a 5 D.O.F reduced simulation model while the controller is based on the 3 D.O.F. reduced control model without affecting the robustness of the controller. [2]

LITERATURE

[1] Mulders P.C.(2), Jansen J., Pijls J.M.L., Optimal trajectory control of a linear robotarm by a state space method CIRP-Annals 1989 , vol 38/1/1989 pp. 359-364

[2] Mulders P.C. (2), Voorkamp R.J., Jansen J., Wolf A.C.H. van der (1) Adaptive control of a modular robot. CIRP Arnuals 1992, vol 41/1, pp. $403-406$.

[3] Mulders P.C., Oosterling J.A.J., Wolf A.C.H. van der (1), A model study of a feeddrive for a numerical controlled lathe CIRP-Annals 1982. Vol 31/3, pp 293-298

[4] Kreffer G.J.

Design of a rotational module and a study of adaptive trajectory control of the RT-robot

WPA 0575 MS thesis, Eindhoven University of Technology,1988

[5] Bax W.H.M.

Study of the dynamic model of a RT-robot.

WPA 0787, MS thesis, Eindhoven University of Technology, 1989

[6] Martens A.P.M.A.

A comparative study and implementation of a trajectory control of a RT-robot.

WPA 0955, MS thesis, Eindhoven University of Technology, 1990

[7] Mulders P.C.(2), Wolf A.C.H. van der, Heuvelman C.J.

Snijder van Wissenkerke M.P.,

A robotarm with compensation for bending

CIRP-Annals 1986, Vol 35/1 pp. 305-308

[8] Craig J.J.

Introduction to robotics, Mechanics and Control

Addison - Wesley, Reading,1986

[9] Asada H., Slotine J.J.E..

Robot analysis and control

John Wiley, New York,1985

[10] Mulders P.C., Martens A.P.M.A., Jansen J.

Model reference adaptive control of a modular robot.

Conference on Mechatronics 1992, University of Dundee, pp. 131 - 135

[11] Koren Y., Malkin S.,

Torque and speed control of DC-servomotors for robots

CIRP-Annals 1984, Vol 33/1, pp. 239-242

[12] Koren Y., Lo C.C

Advanced controllers for feeddrives

CIRP-Annals 1992, Vol 41/2, pp. 689-698

[13] Vastmans L

Direct digital control of feeddrives with microprocessor

PhD thesis, Katholieke Universiteit Leuven,1984

[14] Heeren, T.,

On control of manipulators

PhD thesis, ISBN 90-9002789-0, Eindhoven University of Technology, 1989

[15] Bollinger J.G., Duffie N.A.

Computer Control of Machines and Processes

Addison - Wesley, Reading,1988

vibration shape, i.e. the eigenvectors of the different degrees of freedom - so the relative displacement of the various model masses- leads to the conclusion which masses are loosely coupled and which are rather rigid coupled to each other.

Fig 7 shows the reduced models of 5 D.O.F. (R3,T2), 3 D.O.F. (R2, T1) and 2 D.O.F. (R1, T1) configurations.

The 2 D.O.F. and 3 D.O.F. simulation models are not representative, but with the combination of the 5 D.O.F. as a simulation model and a controller based on the 3 D.O.F. control model rather good results have been obtained, also by implementation in the rotation-translation module.

CONCLUSIONS.

With respect to the objective of obtaining experience in robot design, modelling and testing of advanced control on systems with position dependent parameters the project about the modular robot system has been successful. The translation module is rather stiff due to the hollow frame construction, while the rotation module has a rather low eigenfrequency due to the height and the related additional reduction-stage. 